\title{
Sun Burn Incidence and Knowledge of Greek Elementary and High School Children about Sun Protection
}

\author{
Maria Ioannis Saridii ${ }^{1 *}$, Aikaterini George Toska ${ }^{1}$, Maria Dimitrios Rekleiti ${ }^{2}$, \\ Maria Tsironi², Maria Geitona $^{1}$, Kyriakos Souliotis ${ }^{1}$
}

\begin{abstract}
Introduction: Overexposure to sun radiation and particularly its accumulation during childhood and adolescence is a significant risk factor for skin cancer development. The sun burn is particularly important. Aim: To estimate sun burn incidence in young pupils in a coastal area of Greece. Materials and Methods: Two surveys were conducted in a school population in the same district in Greece, over different periods of time, in young people 9 to 18 years old $(n=2$ 977). Anonymous questionnaires were completed. Levels of significance were twotailed and statistical significance was set at $\mathbf{p}=\mathbf{0 . 0 5}$. SPSS 17.0 software was used for statistical analysis. Results: From the individual characteristics of the participants it was shown that the majority of them had dark hair and fair skin, whereas a significant percentage reported the existence of moles on face and their body (83.4\% vs 68.1\%). The sun burn incidence was high in adolescents and the younger pupils (41.9\% vs 55.6\%). The younger aged children who were living in an urban area had significantly higher rates of sun burn than those living in semi-urban areas $(33.8 \%$ vs $\mathbf{2 4 . 8 \%}, \mathrm{p}=\mathbf{0 . 0 2 0})$. As far as the knowledge of pupils about the risks of sun radiation it was shown that the elementary school pupils had better knowledge than those at high school. Finally, those with better knowledge had the fewer sun burns (Mean 2.83 SD 0.87, p<0.001). Conclusions: The contribution of knowledge to the decrease of sun burn incidence is important as long as this is continuous. Therefore, the education should concern not only children but also teachers and parents in the context of continuous and systematic programs of health education.
\end{abstract}

Keywords: Sunburn - sunscreen - child health - sun exposure - melanoma - Greece

Asian Pac J Cancer Prev, 16 (4), 1529-1534

\section{Introduction}

The exposure to the sun radiation is a significant risk factor of skin cancer development. It is estimated that an individual until the age of 18 will have received the higher rate of ultraviolet radiation (UVR) (50\%-80\%) (Garbe and Leiter, 2009). The skin sensitivity due to the very young age, and the increased stay outdoors, seems that are associated with increased possibility of skin cancer presence in the adulthood (Kanavy and Gerstenblith, 2011). Children have also a less developed pigmentation and a self-defence system and consequently, have a risk of developing skin cancer later in their life (Linabery and Ross, 2008; Wong et al, 2013; Saridia et al., 2014).

The Cutaneous melanoma (CM) of the skin due to its increasing interesting, has been noticeable of several epidemiological studies. Based on these standards the $\mathrm{CM}$ remains in an unusual growth and is perhaps the most aggressive type of cancer. It is referred also as a epidemiological phenomenon due to the mean of its increase in countries as the New Zeeland, Australia, and USA, that has reached 6\%-8\% (Armstrong, 2001;
Livingston et al., 2001; Linabery et al., 2008; Duignan et al., 2014). It seems that 6 out of 10 cases of skin cancers are thought to be caused by excessive exposure to the sun, whereas $\mathrm{CM}$ which is lied in a pre existence melanocytic moles is considerably frequent. Exposure to ultraviolet radiation (UVR) is a major risk factor for developing melanoma, especially when is related to the occurrence of sunburns (particularly in childhood) (Diaz and Diaz, 2013; Gajda and Winciorek, 2014).

Significant risk factors are the phototype of the individual (fair skin, hair and eyes), as well as the location of residency, the heredity and family history. Skin cancer is more common in people with fair skin who spend a lot of time under the sun. The sun burn is a further risk factor of skin cancer developing. At least one episode of sun burn during the childhood increases 1.5-3 times the relevant risk of CM melanoma, whereas over than five sun burns reach the relative risk to 2-6 (Hall et al., 2001; Garbe and Leiter, 2009; Mah et al., 2013).

It is obvious that the main preventive measure of skin cancer is avoiding as much as possible sun exposure. However, given that this is not feasible, there are some 
measures which are considered to be necessary for the protection during the sun exposure. Cotton and light colored clothes, staying in shady places, sun glasses, hat, avoiding exposure during midday hours and use of sunscreen with a high protection factor, are the main measures of sun protection (Cafri et al., 2008; Aalborg et al., 2009; Williams et al., 2013). The indicated protection factor for young individuals is $>30$ and for younger children >50 (Hawryluk et al., 2014; Reinau et al., 2014).

Several countries as well as the World Health Organization (WHO), comprehending the importance of this issue in a worldwide level, have activated prevention programs for the youngest individual and especially in school and athletic environments (WHO, 2003; Saraiya et al., 2004; Miles et al., 2005; Cokkinides et al., 2006; Reynolds et al., 2006; Kyle et al., 2014). All these programs are based on studies which have shown that the continuing awareness of young people from the preschool age combined with parallel awareness of parents, teachers, and other structures, like media, internet and health professionals, contribute to the increasing knowledge on the sun exposure risks and the adoption of rational behaviors against sun radiation (Cokkinides et al., 2006; Gilaberte et al., 2008; Andsoy et al., 2013; Saridi et al., 2014; Williams et al., 2013).

The aim of the study was the estimation of sun burns incidence in young pupils in a coastal district of the country, and the correlation of this incidence with the potential responsible factors .

\section{Materials and Methods}

Two surveys were conducted in school children in the same region of Greece. The first survey was conducted in 2007 in adolescents (16-18 years old), whereas the second was conducted in 2010 in elementary school children (9-12 years old). The knowledge, attitude, beliefs and behaviours were estimated in relation with the risks from the sun radiation as well as the sun protections measures (Saridia et al., 2014; Saridib et al., 2014). An important parameter which was investigated was the sun burn incidence, and all these variables potentially influencing the young peoples' behaviours which can decrease or decrease the sun burns incidence. The instruments used in these two studies were designed according to the WHO guidelines, with additional data from the program Sun smart (WHO, 2003; Miles et al., 2005). They had been checked for validity and reliability [Cronbach's a $=0.79$ - elementary school children and Cronbach's $\mathrm{a}=0.76$ adolescents]. In both cases, before the instruments were used, two pilot standardizations were done and given for face validity to three scientists' with relevancy in epidemiological studies.

The data regarding sunburns, were investigated with the same questions in both groups and were compared. For both studies permission was obtained from the Educational Institute and the Education Ministry. Informed consensus forms were sent to children and parents and anonymity was observed during the whole period of the study. The sample included 815 high school and 2162 elementary school students. The region in which the surveys were conducted, was the district of Corinth, which has mainly urban characteristics and a wide range of coastal areas.

\section{Statistical analysis}

The means and the Standard Deviation or median were used for the description of quantitative variables. The absolute $(\mathrm{N})$ and the relative $(\%)$ frequencies were used for the description of qualitative variables. For the comparison of the quantitative variable between the two groups Student's t-test was used. In order to find the difference among knowledge levels, logistic regression analysis took place and resulted Odds ratio with $95 \%$ confidence intervals $(95 \% \mathrm{CI})$ taking into consideration age, gender, nationality, kilometric distance from the sea, whether they had previously participated in another study, or belonged in high risk groups, as well as their knowledge and attitude score. The significance levels were twotailed and the statistical significance was set to 0.05 . The statistical program SPSS 17.0.was used for the analysis.

\section{Results}

In the study 2.977 individuals (815 high school pupils) and 2162 elementary school pupils participated]. The mean age of the adolescents was $16.6 \pm 1.6$, whereas the elementary school pupils' was $9.5 \pm 1$. The nationality of the sample as it was expected was Greek, and the location of residence in both groups (adolescents and younger children), was for the majority in urban areas (64.5\% vs $72.9 \%$ ). From the individual characteristics of the participants it was shown that the majority had dark hair and fair complexion, whereas a high percentage reported the existence of moles on their face and body $(83.4 \% v s$ $68.1 \%$ ) (Table 1).

The incidence of sun burn for the summer prior to the study, seems to be high enough both in adolescents and younger pupils $(41.9 \%$ vs $55.6 \%)$. The part of the body with the higher incidence was the back (66.7\% vs 62.3\%) followed by the face. According to the description of sunburn, the older children had experienced mainly a light red skin without pain $(60.9 \%)$, whereas younger children reported that the burn was wider with blisters with or without pain (32\% vs 22.4\%) (Table 2).

The use of sunscreen displayed a wide range for the both groups. More specifically, the majority of high school pupils $(97.1 \%)$ reported that they used a sunscreen, whereas those attended elementary school had lower use percentage $(39.5 \%)$. Regarding the indicated sun protection factor ( $\mathrm{spf}>30$ ), it seems that this was equal for the both groups (41.8\%vs $48.6 \%$ ).

Regarding knowledge about the risks of sun radiation, both studies showed a better level of knowledge in younger pupils compared to the older. Specifically, $49.4 \%$ of adolescents and $76.8 \%$ of younger pupils reported that they knew the potential damages of sun exposure for the human organism. On the contrary, adolescents had a better knowledge as far as the damage a sun burn can cause to their health ( $56.8 \%$ vs $38.5 \%$ ), whereas, both groups seems to know equally that the dangerous hours during the day in which sun exposure should be avoided, are between $10.00 \mathrm{pm}$ xa $16.00 \mathrm{am}$ (Table 2).

The sun burn incidence did not display a statistically 
Table 1. Demographics

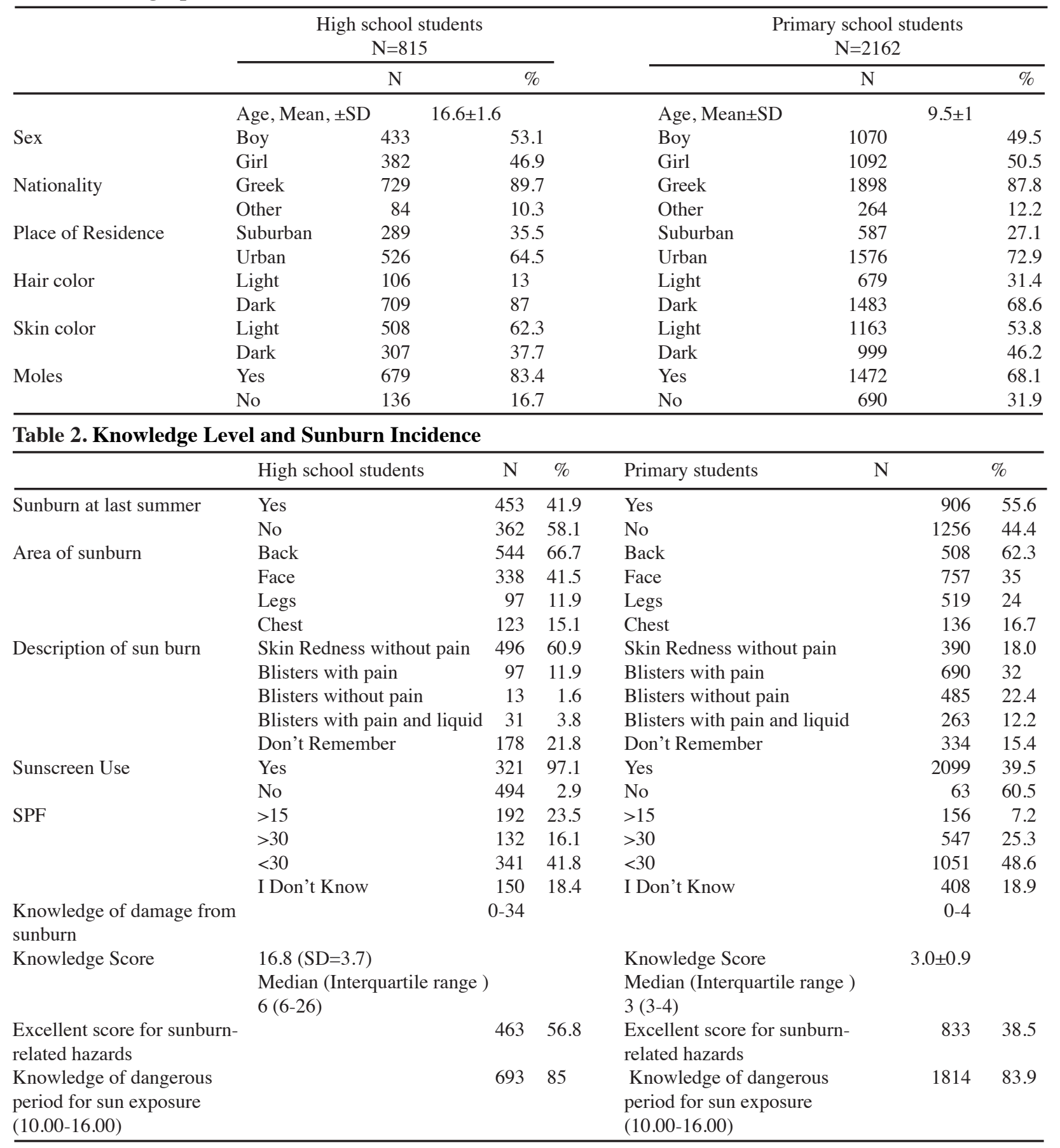

significant difference for both groups as far as the gender $(\mathrm{p}=0.981 \mathrm{vs} \mathrm{p}=0.265)$ and the nationality of the pupils ( $\mathrm{p}=0.226 \mathrm{vs} \mathrm{p}=0.619)$ opposite to the location of residence which seems to be associated with this. Particularly, children living in an urban area had more often a sun burn compared to those living in semi-urban areas for adolescents $(33.8 \%$ vs $24.8 \%, \mathrm{p}=0.020)$, and younger children $(34.4 \%$ vs $29.8 \%$, $\mathrm{p}=0.020)$.

The use of sun screen in individuals which had a sun burn, displayed a variance for both groups of participants, with adolescents reporting a higher sun burn incidence than younger children ( $72.8 \%$ vs $58.5 \%)$. Among all the individuals they used a sunscreen with a high index $(>30)$, higher rates of sun burns reported by the younger children ( $30 \%$ vs $51 \%$, p <0.001). Finally, the percentage of children which referred a history of sun burn, declared that they like to be tanned with the high school children to support more this view $(67.7 \%$ vs $41.7 \%)$. Also, children with fair skin and hair, displayed lower rates of sun burn in adolescents than younger children $(42.3 \%$ vs $44.8 \%$, $\mathrm{p}=0.001)$.

Finally, the correlation between knowledge score and the incidence of sunburn, showed that the better the knowledge about the risks of sunburn, the lower the sunburn incidence (Mean 2.83 SD 0.87, p <0.001, Student's t-test).

\section{Discussion}

AGiven that according to the literature extended sun exposure without protection during childhood and adolescence is a significant risk factor of cancer skin development, (Linabery and Ross, 2008; Wong et al., 
2013) our survey focused on the investigation of those factors which contribute to the adoption of risk health behaviors from the young people. The sun burn incidence is one of the most important related factors. It is estimated that at least one sun burn during childhood and adolescence multiplies the risk of skin cancer later in life (Hoang and Eichenfield, 2000; Armstrong and Kricker, 2001)

Greece is a country where due to the geographic position and climate, there are large periods with sunshine throughout the year and therefore children are exposed more frequently during their activity as well as the wide period of school vacations (Zerefos, 2002; Nikolaou et al., 2009).

However, it has been observed that the school programs of all educational grades (first and secondary education) do not include issues about the risks from sun radiation and sun protection. It has also been observed that there is almost no management in the school environment concerning measures of sun protection during the gym and physical activities.

The data included in this study were about the comparison of data of two similar studies that had taken place in the same area, in different time periods, and those data were discussed according to the knowledge and attitudes of pupils (9-18 years old) on sun protection (Saridi et al., 2012; Saridi et al., 2014a; 2014c). The compared data focused on incidence of sun burn in all age groups, and recorded all these factors which intensify or prevent this incidence.

The sample of the studies included pupils attended elementary and secondary school $(n=2.977)$, in a coastal area of Greece, and the majority lived very close to the beach $(72.9 \%)$. It's obvious that younger pupils have not consolidated their attitudes and beliefs, opposite to the adolescents, and therefore they are the most eligible focus group for the implementation of educational programs according to the social learning theory (Bandura, 1997). According to studies, the adolescents do not change easily their attitudes (Wright et al., 2008; Glanz et al., 2009).

The phototype of the pupils participated in the study, included fair skin and hair, whereas an individual characteristic investigated in both studies, was the recording and mapping of the moles. It was shown that the adolescents $(83.4 \%)$ and the younger pupils (68.1\%) reported several moles in their face and body. The scientific community has emphasized the necessity of a systematic moles' checking by a specialist, whereas the State has been activated via the implementation of control programs focused on general population. (Wright et al., 2008; Aalborg et al., 2009; El-Khateeb et al., 2014; Hawryluk and Liang, 2014; Patruno et al., 2014).

The nationality of the children was Greek $(80 \%)$ whereas the rest of the children were of Albanian or Bulgarian descent. The above data were recorded first in order to study the differences among the results of the questions, and second to illustrate the influence of indigenous and cultural characteristics on the various factors. The investigation of nationality of the sample in similar studies is considered necessary given that may diversify several results (Molgo et al., 2005; Miles at al., 2005; Al-Naggar et al., 2011).
The study of sun burns incidence, showed that the younger aged pupils had a history of a serious sun burn more frequently than adolescents, a fact that causes a great concern. Similar high rates of sun burn were displayed by other studies in many countries (Jones et al., 2007; Cheng et al., 2010; Ergul et al., 2011; Kyle et al., 2014), whereas countries which have activated systematic awareness programs like Australia and USA, have better results (Larsman et al., 2012; Mah et al., 2013; Volkov et al., 2013).

An additional finding of our study which is very concerning is the fact that gender and nationality did not play any role to the sun burn incidence, however in both studies it was observed that pupils residing in urban areas had more frequently experienced a sun burn than those resided in semi-urban areas far from the sea.

In several studies a high incidence of sun burn has been reported in people residing in a coastal area in comparison with those residing in semi-urban and rural areas (Savona et al., 2005; Aalborg et al., 2009; Ramazzotti et al., 2011; Malak et al., 2013; Saridi et al., 2014) and this could be explained by the easy accessibility to the sea and the subsequent extended stay under the sun.

The use of sunscreen is following the same variety with the sun burn with a more extended variety.

More specifically, the majority of adolescents declared that they used sunscreen, opposite to the younger pupils where the low percentage of sunscreen's use was alarming (39.5\%), whereas both groups reported almost equal use of sunscreen with high protection factor $(\mathrm{spf}>30)$. Similar studies are in agreement with our study as far as the use of the right protection factor, demonstrating that regardless if young people reported that are protected from the sun , however, they don't know the importance and the correct spf (Gilaberte et al., 2008; Wright et al., 2008; Ergul et al., 2011; Jones et al., 2013). Generally, the adolescents seem to have a better level of knowledge than younger pupils, perhaps due to the availability and use of wider sources of information as media and the internet (LaBat et al., 2005; Pustisek et al., 2010; Gritz et al., 2013; Duignan et al., 2014).

The correlation between sunscreen use and sunburn incidence showed that those who applied regularly sunscreen had equally high rates of sunburn, and the adolescents' percentage was higher on this occasion. On the contrary, the sample who said they used a sunscreen with spf $>30$ had lower rates of sunburn. The participants who reported having a sun burn, declared they preferred to be tanned, and among those, the adolescents had the higher percentage. Several other studies have also found higher percentages of adolescents using sunscreen and having a sunburn too (Linabery and Ross, 2008; Wright et al., 2008; Al-Naggar et al., 2011; Duignan et al., 2014). Their behavior as far as the acquirement of a tan is following the trends of young people for the acceptable beauty standards, as promoted by the Media, their peers and society, and this has been observed in other countries too (Savona et al., 2005; Saridi et al., 2012; Gefeller et al., 2014; Kyle et al., 2014).

There was a positive finding in our study namely that the youngsters with fair skin had lower incidence of 
sun burn than those with dark complexion. This finding is in agreement with other similar studies and could be attributed to the special increasing sensitivity of fair skin in combination perhaps with the knowledge or parental intervention which is more intensive in these cases, resulting to the uptake of protection sun measures due to the increasing concerns (Cafri et al., 2008; Tripp et al., 2013; Gefeller et al., 2014; Williams et al., 2014).

The results as far as the knowledge levels vary in both age groups. The younger pupils reported they knew the dangerous effects of sun radiation, whereas the adolescents recognized the sun burn as a factor of skin cancer development, but both groups equally recognized that the period in the day where the sun exposure should be avoided is between $10.00 \mathrm{pm}$ to $16.00 \mathrm{am}$, which is very important for the adoption of a correct behavior against the sun radiation. High levels of knowledge of the younger pupils are reported by several studies and specially in those conducted in countries where systematic educational and awareness programs about sun radiation are incorporated in their educational system. (Livingston et al., 2003; Li et al., 2012 McLoone et al., 2014; Reinau et al., 2014; Gefeller et al., 2014). It seems also that the last years this knowledge is better and this could be explained by the fact that in a worldwide level there is an increasing activity and interesting, due to the increasing rates of CM (Dalli et al., 2004; Linabery and Ross, 2008; Wright et al., 2008; Al-Naggar et al., 2011; Ergul et al., 2011).

Finally, it was found that the more knowledge young pupils have, the lower the percentage of sunburns they reported. This is the point where several studies were focused on ,indicating that the intervention and systematic programs enhance the knowledge of pupils from preschool age (Alberg et al., 2002; Cokkinides et al., 2006; Li et al., 2011; Larsman et al., 2012; Suppa et al., 2013; Saridic et al., 2014).

In conclusions, from both studies it was found that despite the students' knowledge level was high, nevertheless their attitude was on a par with that level. The incidence also of sun burns was alarmingly high, although increased knowledge levels contributed significantly to the decrease of that incidence rate.

Correct use of sun screen and its appropriate application seems to fall behind and the burden for this situation falls equally to the school and family environment.

Awareness and education programs should be systematic and continuous, put to practice from pre-school age, and should involve school teachers, families and other community structures.

Sun protection is an important, low cost and high benefit measure of skin cancer prevention.

\section{References}

Aalborg J, Morelli JG, Mokrohisky ST, et al (2009). Tanning increased nevus development in very-light-skinned children without red hair. Arch Dermatol, 5, 989-96.

Alberg A J, Herbs RM, Genkinger JM, et al (2002). Knowledge, attitudes, and behaviors toward skin cancer in Maryland youths. J Adolesc Health, 31, 372-7.

Al-Naggar RA, Al-Naggar TH, Bobryshev YV (2011).
Perceptions and opinions towards skin cancer prevention in Malaysia: a qualitative approach. Asian Pac Cancer Prev, 12, 995-9.

Andsoy II, Gul A, Sahin AO, et al (2013). What Turkish nurses know and do about skin cancer and sun protective behavior. Asian Pac J Cancer Prev, 14, 7663-8.

Armstrong BK, Kricker A (2001). The epidemiology of UV induced skin cancer. J Photochem Photobiol B, 63, 8-18.

Bandura A (1997). Self-efficacy: The exercise of control. W.H. USA: Freeman and Company Pbl.

Buller DB, Buller MK, Reynolds KD (2006). A survey of sun protection policy and education in secondary schools. $\mathrm{J} \mathrm{Am}$ Academy Dermatol, 54, 427-32.

Cafri G, Thompson JK, Roehrig M, et al (2008). Appearance motives to tan and not tan: Evidence for validity and reliability of a new scale. Ann Behav Med, 35, 209-20.

Cheng S, Lian S, Hao Y, et al (2010). Sun-exposure knowledge and protection behavior in a North Chinese population: a questionnaire-based study. Photodermatol Photoimmunol Photomedicine, 26, 177-81.

Cokkinides V, Weinstock M, Glanz K, et al (2006). Trends in sunburns, sun protection practices, and attitudes toward sun exposure protection and tanning among us adolescents, 1998-2004. Pediatrics, 118, 853-64.

Dalli D, Ogce F, Okcin FA (2004). Knowledge of the effects of sun exposure of Turkish high school students and their sun bathing habits. Asian Pac J Cancer Prev, 5, 366-9.

Diaz JH, Diaz JH ( 2013). Updates for responsible sun exposure behavior and photoprotection in the south. J La State Med Soc, 165, 277-82.

Duignan M, Signal L, Thomson G (2014). Good intentions, but inadequate practices - sun protection in early childhood centres, a qualitative study from New Zealand. $N Z$ Med $J$, 127, 40-50.

El-Khateeb EA, Lotfi RA, Abd Elaziz KM, et al 2014). Prevalences of skin diseases among primary schoolchildren in Damietta. Egypt, 53, 609-16.

Ergul S, Ozeren E (2011). Sun protection behavior and individual risk factors of Turkish primary school students associated with skin cancer:a questionnaire-based study. Asian Pac J Cancer Prev, 12, 765-70.

Everett Jones S, O’Malley Olsen E, Michael SL, et al (2013). Association of UV index and sunscreen use among White high school students in the United States. J Sch Health, 83, 750-6.

Garbe C, Leiter U (2009). Melanoma epidemiology and trends. Clin Dermatol, 27, 3-9.

Gefeller O, Li J, Uter W, et al B(2014). The impact of parental knowledge and tanning attitudes on sun protection practice for young children in Germany. Int J Environ Res Public Health, 11, 4768-81.

Gilaberte Y, Alonso JP, Teruel MP, et al (2008). Evaluation of a health promotion intervention for skin cancer prevention is Spain: the SolSano program. Health Promot Intern, 23, 209-19.

Glanz K, McCarty F, Nehl EJ, et al (2009). Validity of selfreported sunscreen use by parents, children, and lifeguards. Am J Prev Med, 36, 63-9.

Gritz ER, Tripp MK, Peterson SK, et al (2013). Randomized controlled trial of a sun protection intervention for children of melanoma survivors. Cancer Epidemiol Biomarkers Prev, 22, 1813-24.

Hall HI, McDavid K, Jorgensen CM, et al (2001). Factors associated with sunburn in white children aged 6 months to 11 years. Am J Prev Med, 20, 9-14.

Hawryluk EB, Liang MG (2014). Pediatric melanoma, moles, and sun safety. Pediatr Clin North Am, 61, 279-91. 
Maria Ioannis Saridi et al

Hoang MT, Eichenfield LF (2000). The rising incidence of melanoma in children and adolescents. Dermatol Nursing, 12, 188-92.

Jones B, Oh C, Corkery E, et al (2007). Attitudes and perceptions regarding skin cancer and sun protection behaviour in an Irish population. J Eur Acad Dermatol Venereol, 21, 1097 101.

Kanavy HE, Gerstenblith MR (2011). Ultraviolet radiation and melanoma. Semin Cutan Med Surg, 30, 222-8.

Kyle RG, Nicoll A, Forbat L, et al (2013). Adolescents' awareness of cancer risk factors and associations with healthrelated behaviours. Health Educ Res, 28, 816-27.

Kyle RG, Macmillan I, Forbat L, et al (2014). Scottish adolescents' sun-related behaviours, tanning attitudes and associations with skin cancer awareness: a cross-sectional study. MJ Open, 4, 005137.

LaBat K, De Long M, Gahring SA(2005). A longitudinal study of sun-protective attitudes and behaviors. Family Consumer Sci Res J, 33, 240-54.

Larsman P, Eklof M, Torner M (2012). Adolescents' risk perceptions in relation to risk behaviour with long-term health consequences; antecedents and outcomes: a literature review. Saf Sci, 50, 1740-8.

Li J, Uter, W, Pfahlberg A, et al (2011). Parental perspective on sun protection for young children in Bavaria. Photodermatol Photoimmunol Photomed, 27, 196-202.

Li J, Uter,W, Pfahlberg A, et al (2012). comparison of patterns of sun protection during beach holidays and everyday outdoor activities in a population sample of young German children. Br J Dermatol, 166, 803-10.

Linabery A M, Ross J A (2008). Trends in childhood cancer incidence in the U.S. (1992-2004). Cancer, 112, 416-32.

Livingston PM, White V, Hayman J, et al (2003). Sun exposure and sun protection behaviours among Australian adolescents: trends overtime. Prev Med, 37, 577-84.

Maksymilian Gajda, Grazyna Kaminska-Winciorek (2014). Do not let to be late: overview of reasons for melanoma delayed diagnosis. Asian Pac J Cancer Prev, 15, 3873-7.

Malak AT, Yıldırım P, Yıldız Z, et al (2013). Effects of training about skin cancer on farmers' knowledge level and attitudes. Asian Pac J Cancer Prev, 12, 117-20.

Mah L, Di Giovine P, Quinn L, et al (2013). Paediatric sunburn: the experience of an Australian paediatric burns unit. $J$ Paediatr Child Health, 49, 654-7.

McLoone JK, Meiser B, Karatas J, et al (2014) .Perceptions of melanoma risk among Australian adolescents: barriers to sun protection and recommendations for improvement. Aust $N$ Z J Public Health, 38, 321-5.

Miles A, Waller J, Hiom S, et al (2005). Sun smart? skin cancer knowledge and preventive behaviour in a British population representative sample. Health Educ Res, 20, 579-85.

Molgó N M, Castillo AC, Valdes FR, et al (2005). Sun exposure behaviors and knowledge. Revista Medica Chile, 133, 662-6.

Nikolaou V, Stratigos AJ, Antoniou C, et al (2009). Sun exposure behavior and protection practices in a Mediterranean population: a questionnaire-based study. Photodermatol Photoimmunol Photomedicine, 25, 132-7.

Patruno C, Scalvenzi M, Megna M,et al (2014). Melanocytic nevi in children of southern Italy: dermoscopic, constitutional, and environmental factors. Pediatr Dermatol, 31, 38-42.

Reynolds KD, Buller DB, Yaroch A L, et al (2006). Mediation of a middle school skin cancer prevention program. Health Psychology, 25, 616-25.

Williams AL, Grogan S, Clark-Carter D, et al (2013). Appearance-based interventions to reduce ultraviolet exposure and/or increase sun protection intentions and behaviours: A systematic review and meta-analyses. $\mathrm{Br} J$
Health Psychol, 18, 182-217.

Wright C, Reeder AI, Gray A, et al (2008). Child sun protection: sun-related attitudes mediate the association between children's knowledge and behaviours. J Paediatrics Child Health, 44, 692-8.

Pustisek N, Sikanic-Dugic N, Hirsl-Hecej V, et al (2010). Acute skin sun damage in children and its consequences in adults. Coll Antropol, 34, 233-7.

Ramazzotti V, Cercato MC, Terrenato I, et al (2011). Skin cancer risk factors in childhood: findings of a survey conducted within Italian areas with a different incidence of melanoma. Epidemiol Prev, 35, 82-8.

Reinau D, Meier CR, Gerber N, et al (2014). Evaluation of a sun safety education programme for primary school students in Switzerland. Eur J Cancer Prev, 23, 303-9.

Saraiya M, Glanz K, Briss PA, et al (2004). Interventions to prevent skin cancer by reducing exposure to ultraviolet radiation: a systematic review. Am J Prev Med, 27, 422-6.

Saridi M, Toska A, Rekleiti M, et al (2012). Sun-protection habits of primary students in a coastal area of Greece. J Skin Cancer, 2012, 629652.

Saridi Ma, Rekleiti M, Toska A, et al (2014). Skin cancer prevention and sun protection habits in children. epidemiology I - Theory, Res Practice, $1^{\text {st }}$ Edition , Concept Press Ltd.

Saridi MIb, Rekleiti MD, Toska AG, et al (2014a). Assessing a sun protection program aimed at Greek elementary school students for malign melanoma prevention. Asian Pac J Cancer Prev, 15, 5009-18.

Saridi Mc, Toska A, Rekleiti M, et al (2014). An educational intervention in primary school students regarding sun protection: a pilot study. Primary Health Care, 4,1.

Savona MR, Jacobsen MD, James R, et al (2005). Ultraviolet radiation and the risks of cutaneous malignant melanoma and non-melanoma skin cancer: perceptions and behaviours of Danish and American adolescents. Eur J Cancer Prev, 14, 57-62.

Suppa M, Cazzaniga S, Fargnoli MC, et al (2013). Knowledge, perceptions and behaviours about skin cancer and sun protection among secondary school students from Central Italy. J Eur Acad Dermatol Venereol, 27, 571-9.

Tripp MK, Vernon SW, Gritz ER, et al (2013). Children's skin cancer prevention: a systematic review of parents' psychosocial measures. Am J Prev Med, 44, 265-73.

Volkov A, Dobbinson S, Wakefield M, et al (2013). Seven-year trends in sun protection and sunburn among Australian adolescents and adults. Aust N Z J Public Health, 37, 63-9.

Wong JR, Harris JK, Rodriguez-Galindo C, et al (2013). Andersson C, Engardt M (2010). European ozone in a future climate: Importance of changes in dry deposition and isoprene emissions. J Geophysical Res: Atmospheres, 115.

World Health Organization (2003). Sun protection and schools: how to make a difference. Geneva.

Wright C, Reeder AI, Gray A, et al (2008). Child sun protection: sun-related attitudes mediate the association between children's knowledge and behaviours. J Paediatrics Child Health, 44, 692-8.

Zerefos CS (2002). Long-term ozone and UV variations at Thessaloniki, Greece. Physics Chemistry Earth, 27, 455-60. 